\title{
Promoting Children's Mental, Emotional, and Behavioral (MEB) Health in All Public Systems, Post-COVID-19
}

\author{
Kimberly Eaton Hoagwood ${ }^{1,2}$ (D) William Gardner ${ }^{3} \cdot$ Kelly J. Kelleher $^{4,5}$
}

Accepted: 1 March 2021 / Published online: 22 March 2021

( ) The Author(s), under exclusive licence to Springer Science+Business Media, LLC, part of Springer Nature 2021

\begin{abstract}
The COVID-19 pandemic exacerbates the mental, emotional, and behavioral (MEB) health problems of children and adolescents in the United States (U.S.). A collective and coordinated national economic and social reconstruction effort aimed at shoring up services to promote children's MEB, like the Marshall Plan that helped rebuild Europe post-World War II, has been proposed to buttress against the expected retrenchment. The plan prioritizes children's well-being as a social objective. We propose strategically reconstructing the public safety-net systems serving youth, including early education, maternal and child health, child welfare, corrections, and mental health. That plan called for a concentrated focus on coalition-building and contracting by state mental health systems to establish a foundation for an improved health system. This paper offers a complementary set of suggestions for the four non-mental health systems mentioned above by recommending actionable steps based on scientific evidence to support improved services for children at risk for MEB problems. For each system we describe examples of evidence-informed services, policies or programs that (1) prevent disabilities and promote health, (2) protect and preserve families and neighborhoods, and (3) provide quality care. Prioritizing the promotion of children's MEB health by all state systems can shape U.S. children's health and well-being for generations to come.
\end{abstract}

Keyword Early childhood education Mental Health · Child welfare system · Corrections · Incarceration · Maternal and child health $\cdot$ Public health $\cdot$ Policymaking $\cdot$ United States

\section{Introduction}

The prevalence of children's psychological disorders is $17.4 \%$, and rates for anxiety, depression and suicide are steadily increasing (Cree et al. 2018; Mojtabai et al. 2016). Glaring racial and ethnic disparities exist in access to and quality of mental health services (Merikangas et al. 2011).

Kimberly Eaton Hoagwood

Kimberly.hoagwood@nyulangone.org

1 Department of Child and Adolescent Psychiatry, New York University, New York, NY, USA

22543 Painter Court, Annapolis, MD 21401, USA

3 Senior Research Chair in Child and Adolescent Psychiatry, Children's Hospital of Eastern Ontario Research Institute and Professor of Epidemiology, University of Ottawa, Ottawa, ON, Canada

4 Abigail Wexner Research Institute At Nationwide Children's Hospital, Columbus, OH, USA

5 The Ohio State University College of Medicine, Columbus, OH, USA
Contributing to both prevalence and service disparities, $18 \%$ of children lived in poverty, and $33 \%$ had parents who lacked stable employment before COVID. These situations are worsening with the pandemic. The combination of rising rates of children's disorders, a high poverty rate, high unemployment, limited schooling and services, and the escalating financial crisis posed by COVID-19 threaten healthy development for this generation of children.

To counter these threats, we need a plan that prioritizes social responsibility for children's well-being and encompasses all public systems serving children. Hoagwood and Kelleher (2020) outlined core principles for such a response. They called for a fundamental societal shift to redress generations of public service system neglect of children. Modeled on the Marshall Plan, they outlined an economic and social reconstruction effort whose cornerstone is a childrenfirst ethic: a societal pivot to prioritize children's healthy development. The plan calls for the equitable coordination of public systems serving children and youth: mental health, early learning and education, maternal and child health, child welfare, and corrections. Given that the vast 
majority of MEB challenges begin before age 14, the plan would move services upstream to promote children's early development and support families, thereby mitigating the well-documented risks that lead to later mental, emotional and behavioral (MEB) disorders.

The children's mental health system in this country was not managing the pre-pandemic demand for services. By itself, it will not be able to address the predicted surge in demand post-COVID-19. But scientific evidence points to a multitude of community-facing programs, policies, and strategies that prevent mental health problems from developing in the first place and promote children's MEB health by addressing child and family developmental needs early in life. The National Academies of Science, Engineering and Medicine (NASEM) has called for all sectors of society to engage in the healthy development of resilient children by strengthening families and communities (National Academies of Sciences Engineering \& Medicine, 2017a, 2017b, 2019a). Effective strategies to promote healthy development and to address the negative consequences of racism on families and communities can be implemented using a multi-sector, coordinated plan; in fact, numerous state and local pediatric population health experiments were doing that before COVID-19.

Hoagwood and Kelleher (2020) outlined actionable steps that state and local mental health systems could undertake to move services upstream. These included coalition building with other systems. These coalitions were strengthened by contracts that improved accountability for outcomes, including required metrics to measure those outcomes. Coalition building includes establishing the structural conditions for implementing a prevention/promotion initiative, workforce issues (i.e., who will carry the program out), and engaging communities and families in the effort. Contractual considerations include establishing agreed-upon measures and metrics to monitor outcomes, assigning accountability for those outcomes and delineating realistic time frames for these investments before expecting improved outcomes.

In this paper, the authors extend the plan to non-mental health systems, with suggestions about scientifically based services programs or policies that can be immediately mobilized, including under-represented racial minority children who may be particularly vulnerable because of ongoing systemic racism and pandemic effects. The abrupt shutdown of many state public services and the economic recession has further weakened the public safety net infrastructure. Nevertheless, the disruption also provides an opportunity to commit to social priorities that focus on upstream services targeted at children's healthy mental, emotional, and behavioral development.

While space precludes our discussion of financing issues-those will be addressed in future papers-there is strong evidence supporting the positive return of early investments in children (National Academies of Sciences Engineering \& Medicine, 2016, 2017a, 2017b, 2019a), and benefit-cost ratios have also been calculated for many early education programs (Institute \& for Public Policy.Benefit-Cost Results: Children's Mental Health.In:, 2020:https: www.wsipp.wa.gov, BenefitCosttopicId $=5$. 2020) (see https://www.wsipp.wa.gov/BenefitCost). Creative financing strategies have also been developed to support early education initiatives, which have longer-range return-on-investments (Foundation et al. 2018) and are now being used by several states (Hoagwood et al. 2020). New federal investments are also testing these models of care nationally (i.e., Integrated Care for Kids (IncK.) (Care and for Kids (InCK) Model. 2020; https: Innovation.cms.gov, Innovation-models, Integrated-care-for-kids-model.Accessed 09, 03, 2020, 2020. 2020).

To address the "historic underinvestment" in children's MEB (Flores \& Lesley, 2014; Kayal, 2016), we suggest three core actions that child-serving public systems can adopt to mitigate the mental health consequences of the pandemic. These are to: (1) promote health and prevent risks, (2) protect and preserve public structures that work, and (3) provide care for all populations. These actions will increase the availability of mental health-promoting services in nonmental health systems and enable delivery of mental health promotion services to children and families who cannot access the mental health system.

We recognize that other critical system supports are needed to strengthen system capacity, and other papers and NAM reports () have called for better policy, data infrastructure, implementation support, and workforce development. This paper is focused solely on innovative, science-based programming for non-mental health sectors that can promote children's mental health and ability to thrive. We outline below the core elements of this plan for four sectors: early education, maternal and child health, child welfare, and corrections.

\section{Four Sectors}

\section{Early Learning and Education}

Early brain development begins in utero, and critical neural pathways and processes occur during the first years of life. Scientific evidence has established how and why investments in early childhood education pay off; the seminal Neurons to Neighborhoods synthesized evidence about the impact of the environment (i.e., families, neighborhoods, communities, and schools) on the development of children's language, cognition, and behavior (National Research Council, 2000). The zip code where you spent your first years is associated with health and economic outcomes later in life (National 
Academies of Sciences Engineering \& Medicine, 2017a, $2017 b)$. Two decades of research have also documented how parenting matters, focusing on specific parent-child interactions that promote development (National Academies of Sciences Engineering \& Medicine, 2016).

States can take initiatives to foster early learning and development. Early education systems can prevent adverse outcomes, promote health, and provide equitable services supporting children's MEB health.

\section{Prevent Disruptions to Early Brain Development and Promote Early Learning}

Adverse childhood experiences, or ACEs, can derail early children's development (Felitti et al. 1998) and lead to costly downstream healthcare spending (Miller et al. 2020). ACEs screenings, developed initially for adults, have been modified for use for children and adolescents (self-report), are increasingly integrated into pediatric well visits and used in prenatal care (Atzl et al. 2019). Forty-eight states and D.C. have, since 2009, included at least one question on ACEs (via a national survey, BRFSS). But only the state of California mandates universal ACEs screening (e.g., via pediatric well visits before school entry) through their Medicaid program, Medi-Cal. While ACEs screening is important, to be effective it must be coupled with care coordination and availability of services. Thirty-seven states now have standardized referral forms and processes to link families to services (Academy \& for State Health Policy. Referral $\&$ Care Coordination.In. Healthy Child Development State Resource Center, 2020).

Early education (from birth through age 5) has been shown to provide long-term benefits. The High/Scope Perry Preschool study was the first to show early education's large effects on educational attainment, income, criminal activity, and other important life outcomes. The Perry Preschool effects were sustained well into adulthood, and morerecently reported that high-quality birth-to-five investments in early childhood education, rather than preschool alone, resulted in a 13\% return on investment (García et al. 2020). The federally-funded Early Head Start (pregnant mothers and children up to age 3) and Head Start (children ages 3-5) programs provided services to nearly 1 million pregnant women and children in fiscal year 2019 (). Early Head Start has been shown to improve child development and health and parent engagement with their children (Mayoral, 2013); see Section C below for child welfare-Head Start partnership examples.

\section{Protect and Preserve}

Early education programs that strengthen and empower parents to provide high-quality interactions with their children (i.e., "serve and return"). These programs can be delivered through local community health organizations, neighborhood level programs, or in pediatric practices (National Scientific Council on the Developing Child. Connecting the Brain to the Rest of the Body: Early Childhood Development \& Lifelong Health Are Deeply Intertwined: Working PaperNo., 152020). These include Healthy Steps, an evidence-based, team-based pediatric primary care program that promotes the health and well-being and school readiness of infants and young children (www.healthysteps.org), and Triple-P, an evidence-based parenting program that teaches strategies to encourage children's development and manage their behavior. Triple $\mathrm{P}$ has also been tested in the child welfare system, with proven reductions in child maltreatment, child out-of-home placements, and child maltreatment (Prinz et al. 2009).

\section{Provide Services that Build Early Learning into the Continuum of Programming}

States are exploring and investing in high-quality early learning and development programs. Many of these investments are prompted by the need to deliver value-based services, especially in state Medicaid programs. One program is the First 1,000 Days of Medicaid initiative in New York State, which recognizes the impact of early learning and development in the first three years on lifelong health outcomes. The program delivers care beyond the traditional medical model to address social determinants of health, including poverty, racism, and other environmental influences during the first 1,000 days (i.e., three years) of life. Nationally, home visiting programs in early pregnancy have some of the best evidence and provide roadmaps for many states to improve child development. Similarly, many states are adopting early childcare and preschool interventions to achieve early learning gains.

\section{Maternal and Child Health}

Over the last two decades, scientific progress demonstrated the critical importance of maternal and child health from pre-conception through the first two years of life in healthy brain development and overall mental, emotional, and behavioral wellness (National Academies of Sciences Engineering \& Medicine, 2019a). The refinement of decades of risk factor and resilience research into both biological systems science, explaining life-course effects through environmental effects on gene expression and protein synthesis, combined with an improved understanding of community and societal level effects on development, has yielded comprehensive models of both the biology and likely targets for intervention. 
Unfortunately, rates of maternal and infant mortality in the U.S. are among the highest of all developed countries. Lack of attention to maternal health before, during and after pregnancy leads to a cascade of negative events including prematurity, congenital anomalies, as well as lifelong disabilities and special educational needs. In addition, the mortality rate in the US is 40.8 for blacks, 29.7 for $\mathrm{AI} / \mathrm{NA}$, and 12.7 for whites. (https://www.cdc.gov/media/releases/2019/ p0905-racial-ethnic-disparities-pregnancy-deaths.html). To maximize MEB health in children and adolescents, state maternal and child health systems should prevent preterm births, preserve maternal-child bonds, and provide services that enhance early relationships among parents and children.

\section{Prevent Premature Births}

The prevention of prematurity remains an elusive goal in many communities despite gradual progress over the past decade in the U.S. Various interventions are associated with reductions in prematurity, including increased birth spacing, vaginal progesterone for pregnant women at risk, and calcium supplements during pregnancy (Osman et al. 2018). One of the best-supported strategies is smoking cessation during pregnancy. Women who are pregnant and provided professional smoking cessation have higher birth weights and less preterm birth. Smoking initiation often occurs after delivery, but the benefits of quitting during pregnancy are substantial (World Health Organization 2020) https://www. euro.who.int/en/data-and-evidence/evidence-informed-policy-making/publications/hen-summaries-of-network-membe rs-reports/how-effective-are-smoking-cessation-and-nutri tional-interventions-in-preventing-low-birth-weight.Acces sed 09/03/2020).

\section{Preserve the Maternal-Child Bond}

Parent-child attachment is a cornerstone for healthy child mental, emotional and behavioral (MEB) development. One of the most common threats to that bond is maternal depression. Maternal postpartum depression occurs in $10 \%$ of women and is associated with cognitive and emotional delays and disorders in children (Zhou et al. 2019). Maternal depression screening and treatment are associated with improvement in child development and emotions (Cuijpers et al. 2015). Both antidepressants and psychotherapy demonstrate effectiveness in the treatment of postpartum depression. Unfortunately, many women with postpartum depression do not receive adequate psychotherapy, with depressed black mothers experiencing more adversity and receiving fewer services than others. (https://www.ncbi.nlm.nih.gov/ pmc/articles/PMC3253390/\#!po=27.7778).

\section{Provide Services for Young Families}

Most but not all infants and young children are accessible through well childcare for important detection of early speech, auditory, language, cognitive and emotional problems. Moreover, early intervention at this age is often more effective than later treatment. As such, healthcare services play a critical role in child development intervention before school age.

Many of these interventions have a broad impact at a low cost. For example, the Reach out and Read parent/child literacy program is a book distribution program designed for implementation in healthcare offices. This program allows clinicians to 'prescribe' books with instructions on parentto-child reading, taking good advantage of their established relationships with parents. The program increases parent-child interaction, improves child vocabulary, and makes school and reading more enjoyable (Obus et al. 2017).

\section{Child Welfare}

Child welfare is a large and critical responsibility of state systems: child abuse and neglect affect up to 6 million children in the U.S., costing state and federal governments \$25 billion annually (Council \& of State 2020) https: www.ncsl. org, research, human-services, child-welfare.aspx.Accessed 08, 11, 2020). In 2018, the U.S. foster care system served 687,345 children. Preventing the removal of children from their families is the goal of child welfare systems unless they are in imminent danger. However, only $56 \%$ of foster children have case-plan goals of reunification with their families (U.S., 2019). Services and supports that empower parents to improve interactions with their children, contribute to their health and well-being, and ensure safe home environments can prevent removal from their homes.

Abuse and neglect alter both physiological (e.g., brain development) and psychological development (e.g., impacting attachment and relationship skills), which, when left untreated, have profound and often generational consequences. Safe, stable, nurturing relationships can buffer childhood adversity (Schofield et al. 2013). Effective statelevel strategies for preventing and treating abuse and neglect include family preservation, family and parent engagement, home-visiting, parenting skills programs, trauma-focused therapies, and professional practice reforms. One systemic impediment to better care for these families is the lack of organizational capacity to implement evidence-based practices (e.g., inadequate training, poor organizational culture.)

\section{Prevent Removal}

To improve the uptake of evidence-based practices in the child welfare system, The Family First Prevention Services 
Act (FFPSA)(2018) established the Title IV-E Prevention Services Clearinghouse to conduct "objective and transparent reviews" of research on programs and services that prevent entry into the foster care system. A critical feature of the act is that states can now spend FFPSA dollars on evidencebased prevention services and programs that allow youth to stay with their parents or relatives. Previously, funds could only be used for foster care costs.

Federal child welfare legislation over the last two decades (Family Preservation and Family Support Provisions of PL103-66) has promoted family support programs as a way to engage child welfare-involved families better. These programs view parents as partners rather than adversaries. The core services of these family support programs are primarily parent education. Programs with the strongest effects on parenting behaviors and outcomes for children are those delivered by professional staff in a group format (e.g. multifamily group therapy). In addition, family peer support services, the provision of peer support by trained parent peers who have themselves received family services, has grown over the last decade. Family peer support is now a Medicaidbillable service in 32 states (Schober \& K., 2020).

Several in-home parent training programs are effective in targeting the risk factors for child neglect and physical abuse. One of these programs is SafeCare, ${ }^{\circledR}$ whose three modules focus on: (1) interacting positively with children, (2) improving the home environment, and (3) maintaining good child health and health records. Parents as Teachers has a similar focus but extends beyond home visiting to include supportive group connection events, child health and developmental screenings, and community resource networks.

\section{Preserve Family Unity}

Youth in foster care often have severe and complex behavioral and mental health problems that put them at higher risk for poorer long-term outcomes (Halfon et al. 1995) and even the youngest children (12-18 months) are impacted (Horwitz et al. 2013). Evidence-based programs that focus on preserving the family unit include Homebuilders, ${ }^{\circledR}$ a home- and community-based intensive family services treatment program to avoid unnecessary foster care placement (or group care, psychiatric hospitals, or juvenile justice facilities).

\section{Provide Services}

As described above, Early Head Start is a federally-funded, two-generation program that combines high-quality early education of young children with parent education and support. New findings show that children enrolled in EHS had fewer child welfare encounters and lower child maltreatment rates than non-EHS-enrolled children (Green et al., 2014).
Recent federal attention has focused on helping community Early Head Start programs partner with child welfare agencies and specific strategies and targeted methods for engaging families (U.S., 2020b).

A recent national policy simulation model shows that balancing child welfare system investments in prevention and treatment generates a positive return on investment, resulting in 3 to $7 \%$ net cost reductions (approximately $\$ 5.2$ billion to $\$ 10.5$ billion saved against the current baseline of $\$ 155.9$ billion) for a cohort of children born over five years (Ringel et al. 2018).

\section{Corrections}

Mass incarceration has deep and racist roots in the U.S. Tragically, the use of jail and prison time exploded over the past 40 years when the number of people incarcerated increased from 500,000 to 2.3 million with marked disparities by race, ethnicity, and income. As a result, an estimated 5 million U.S. children will experience parental incarceration. The emotional, developmental, and financial costs to families with young children experiencing parental incarceration are just now being understood. Consequences include increased homelessness, dependence on public aid, residential instability, school failure, and MEB disorders. These outcomes, combined with growing concern about rising prison and jail costs at federal, state, and local levels, have many policymakers questioning the extensive use of incarceration as a political and social management tool.

To foster healthy development, justice systems should seek alternatives to parental incarceration, preserve parent-child bonds and parenting, and provide services to children of incarcerated parents specific to the traumas experienced by these young people.

\section{Prevent Parental Incarceration}

Mental health and substance abuse diversion programs in criminal courts provide alternatives to the large numbers of persons with behavioral disorders in U.S. jails and detention centers. These courts involve screening persons for drug use or mental disorders, conducting a comprehensive assessment for diagnosis and functional status, and negotiating between behavioral staff and criminal justice staff about appropriate placement (Loong et al. 2016). The target population does not qualify for a not-guilty-by-reason-of-insanity plea but still has significant behavioral disorders. When an agreement is reached for those persons, charges may be dropped or waived in exchange for treatment services. These courts have lower rates of recidivism and public costs (Schneider, 2010; Schneider et al. 2000).

Another option for avoiding parental incarceration is intensive residential or alternative community settings for 
non-violent offenses. Best practices for community settings for serving incarceration may still allow child engagement, but also require: (1) limiting contact with antisocial networks and supporting positive peer relationships, (2) maintaining proximity to home communities, (3) involving families in visitation and planning, and (4) structured schedule and training to avoid negative situations and recognize cues for escalation (National Research Council, 2013). Evidence suggests that when parents have to be separated from children, these community options allow greater interaction with children (Peterson et al. 2019).

House arrest, especially when combined with electronic home monitoring systems, is another option for courts to consider in parent sentencing. Although house arrest with monitoring does not lower recidivism rates, it is less expensive than prison, and it can keep the parent engaged with his or her family (Avdija \& Lee, 2014). A related strategy is to provide early MEB treatment to those on parole or probation as a means to avoid criminal behavior and arrests.

\section{Preserve Parent-Child Relationships}

Even when parents are incarcerated, steps can be taken to preserve parent-child relationships. New initiatives to do this are underway with funding from the National Institute of Justice with special attention to child development, communication and discipline of children, and helping separated parents communicate with their children. For example, Franklin County, Ohio was funded to conduct parent training classes for resident inmates and provide related materials to the child's custodial parent outside of the facilities. Besides regular classroom instruction and didactics, the program helped inmates communicate with their children by mail, email and phone.

Among the challenges in preserving relationships are inconsistent and punitive prison and jail visitation policies or even children's outright exclusion. The development of family-friendly and transparent visitation centers and policies across the country is an important next step to preserve and build upon parent-child relationships (Axelson et al. 2020).

\section{Provide Services}

Many children are adversely affected by the arrest and incarceration of parents. A small body of literature suggests that behavioral health disorders are common among these children. As a result, clinical settings that care for children should provide them with the best possible services, including a welcoming setting, screening to identify children with families affected by incarceration, and improved access to behavioral health services, with an emphasis on traumainformed care. The stigma associated with incarceration makes it difficult for the custodial parent or the child to identify themselves. Providing easily-seen information at key places, informal screening procedures, and offers of help may increase identification.

In addition to behavioral health services, there are several programs designed for children of incarcerated parents. For example, the Sesame Street Series "Little Children-Big Problems" presents a way to talk with a young child with an incarcerated parent (see https://sesamestreetincommunities. org/topics/incarceration/) (Street \& in Communities. Coping With Incarceration. Sesame Street in Communitieshttps:, , sesamestreetincommunities.org, topics, incarceration, xxxx). Big Brothers-Big Sisters has the Amachi Program (https:// www.bbbs.org/amachi/) that provides mentors for adolescents with an incarcerated parent (Sisters \& of America. Amachi Program: Mentoring For Children With Incarcerated Parents.https: www.bbbs.org, amachi, xxxx). Summer camps organized for children with incarcerated parents help reduce the stigma associated with the justice system involvement.

\section{Conclusion}

The Children-First Marshall Plan is founded on an ethic that recognizes children have the human right to grow up in environments that promote their mental, emotional and behavioral well-being. The economic collapse of Europe following the Second World War created an urgent need to protect the next generation of children and youth, just as the pandemic does today. The original Marshall Plan sought to revive those economies; in this paper, we call for a ChildrenFirst Marshall plan to protect the next generation by restoring and improving cross-system child services.

Because the science of child development has advanced substantially in the past two decades, we can lay out program, policy and investment strategies that can alter the course of children's development during and after the COVID pandemic. In our previous paper (Hoagwood \& Kelleher, 2020), we argued that the mental health system should expand upstream services to protect and promote children's MEB health, and we described how to implement these strategies through coalition-building and innovative contracts. This paper offers complementary recommendations for non-mental health systems. Figure 1 provides examples of these strategies.

Facing a pandemic that threatens our children's healthy development, we need state and national attention to programs and policies that coordinate all public systems that serve children and families. Several professional associations (APA, MHA) have recently proposed creating a White House Office on Children and Youth and a federal Children's Cabinet. Guided by an ethic that measures success by 


\section{How Child-Serving Public Systems Can Build Back Better (BBB) Post-COVID 19}

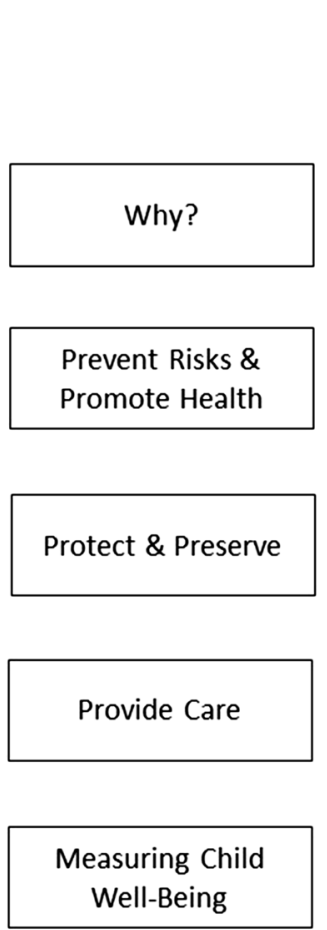

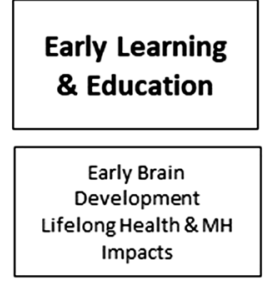
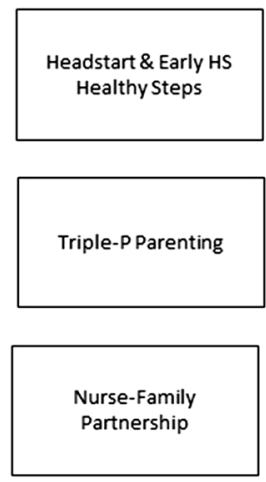
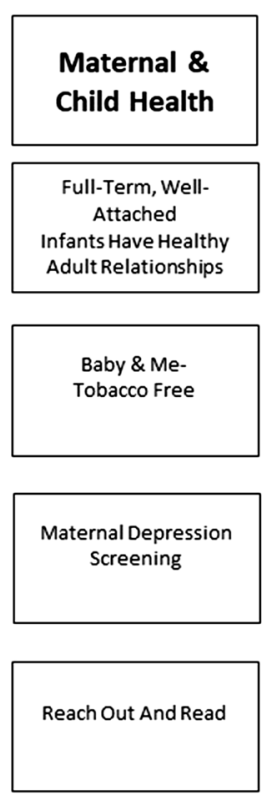
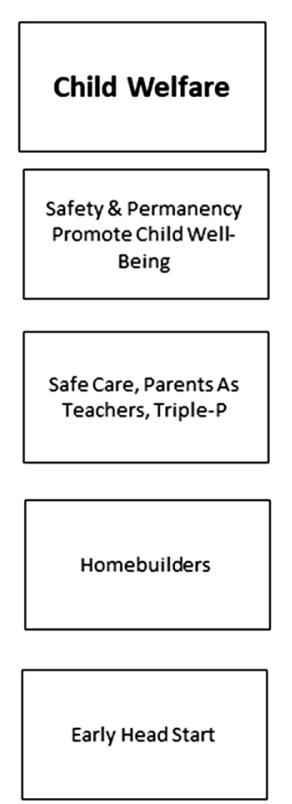

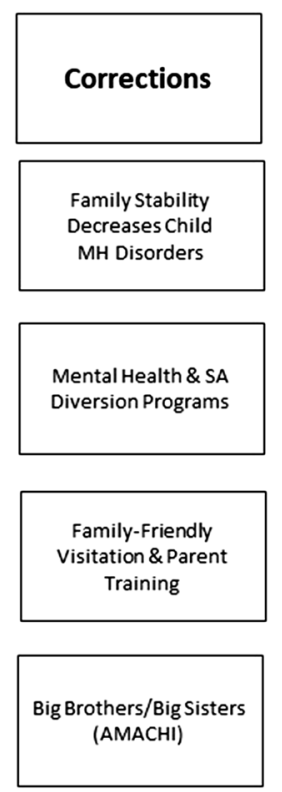

Why: Align Services with Needs, Foundation for Evaluation What: Link data in Schools, Health, CPS, Corrections How: Admin Data Warehouse, with Linkages and Security Whom: Built by Stakeholders, For Stakeholders

Fig. 1 Core policy and program elements in four sectors

healthy children's outcomes, we should act now to provide a continuum of services to intervene early and as often as needed, and an infrastructure that monitors both the quality of services and children's well-being.

\section{Compliance with Ethical Standards}

Conflict of interest The authors have no relevant financial or non-financial interests to disclose. The authors have no conflicts of interest to declare that are relevant to the content of this article. All authors certify that they have no affiliations with or involvement in any organization or entity with any financial interest or non-financial interest in the subject matter or materials discussed in this manuscript. The authors have no financial or proprietary interests in any material discussed in this article.

Research involving human or animal participants Not applicable.

Informed consent Not applicable.

\section{References}

Atzl, V. M., Narayan, A. J., Rivera, L. M., \& Lieberman, A. F. (2019). Adverse childhood experiences and prenatal mental health: Type of ACEs and age of maltreatment onset. Journal of family psychology., 33(3), 304.

Avdija, A. S., \& Lee, J. (2014). Does electronic monitoring home detention program work? Evaluating program suitability based on offenders' post-program recidivism status. Justice Policy Journal., 11(1), 1-15.

Axelson, A., Kelleher, K., Chisolm, D., \& Boch, S. (2020). "How do I help this kid adjust to what real life is for them?": Youth service providers experiences on supporting children with incarcerated parents. Children and Youth Services Review., 110, 104802.

Big Brothers Big Sisters of America. Amachi Program: Mentoring For Children With Incarcerated Parents. https://www.bbbs.org/ amachi/.

Cree, R. A., Bitsko, R. H., Robinson, L. R., et al. (2018). Health care, family, and community factors associated with mental, behavioral, and developmental disorders and poverty among children aged 2-8 years-United States, 2016. Morbidity and Mortality Weekly Report., 67(50), 1377.

Cuijpers, P., Weitz, E., Karyotaki, E., Garber, J., \& Andersson, G. (2015). The effects of psychological treatment of maternal depression on children and parental functioning: a meta-analysis. European child \& adolescent psychiatry., 24(2), 237-245.

Felitti, V. J., Anda, R. F., Nordenberg, D., et al. (1998). Relationship of childhood abuse and household dysfunction to many of the leading causes of death in adults: The Adverse Childhood Experiences (ACE) Study. American journal of preventive medicine., 14(4), 245-258.

Flores, G., \& Lesley, B. (2014). Children and US federal policy on health and health care: seen but not heard. JAMA pediatrics., 168(12), 1155-1163. 
García, J. L., Heckman, J. J., Leaf, D. E., \& Prados, M. J. (2020). Quantifying the Life-Cycle Benefits of an Influential Early-Childhood Program. Journal of Political Economy., 128(7), 000-000.

Halfon, N., Mendonca, A., \& Berkowitz, G. (1995). Health status of children in foster care: The experience of the Center for the Vulnerable Child. Archives of Pediatrics \& Adolescent Medicine., 149(4), 386-392.

Hoagwood KE, Kelleher KJ. A Marshall Plan for Children's Mental Health After COVID-19. Psychiatric Services. 2020:appi. ps. 202000258.

Hoagwood KE, Kelleher K, Counts NZ, Brundage S, Peth-Pierce R. Preventing Risk and Promoting Young Children's Mental, Emotional, and Behavioral Health in State Mental Health Systems. Psychiatric Services. 2020:appi. ps. 202000147.

Horwitz, S. M., Hurlburt, M. S., Heneghan, A., et al. (2013). Persistence of mental health problems in very young children investigated by US child welfare agencies. Academic pediatrics., 13(6), 524-530.

Institude of Medicine. (2011). Child and Adult Care Food Program: Aligning Dietary Guidance for All. The National Academies Press.

Institute of Medicine, National Research Council. Child and Adolescent Health and Health Care Quality: Measuring What Matters. Washington, DC: The National Academies Press; 2011.

Institute of Medicine, National Research Council. New Directions in Child Abuse and Neglect Research. Washington, DC: The National Academies Press; 2014.

Institute of Medicine, National Research Council. Strategies for Scaling Effective Family-Focused Preventive Interventions to Promote Children's Cognitive, Affective, and Behavioral Health: Workshop Summary. Washington, DC: The National Academies Press; 2014.

Integrated Care for Kids (InCK) Model. 2020; https://innovation.cms. gov/innovation-models/integrated-care-for-kids-model. Accessed 09/03/2020, 2020.

Kayal M. The share of federal spending on kids just hit its lowest level since 2016. In. First Focus on Children: The Blog: First Focus on Children.

Loong, D., Bonato, S., \& Dewa, C. S. (2016). The effectiveness of mental health courts in reducing recidivism and police contact: a systematic review protocol. Systematic Reviews., 5(1), 123.

Mayoral, M. V. (2013). Early Head Start fact sheet. Zero to Three.

Merikangas, K. R., He, J.-P., Burstein, M., et al. (2011). Service utilization for lifetime mental disorders in US adolescents: results of the National Comorbidity Survey-Adolescent Supplement (NCS-A). Journal of the American Academy of Child \& Adolescent Psychiatry, 50(1), 32-45.

Miller, T. R., Waehrer, G. M., Oh, D. L., et al. (2020). Adult health burden and costs in California during 2013 associated with prior adverse childhood experiences. PLOS ONE, 15(1), e0228019.

Mojtabai, R., Olfson, M., \& Han, B. (2016). National trends in the prevalence and treatment of depression in adolescents and young adults. Pediatrics, 138(6), e20161878.

National Academies of Sciences Engineering and Medicine. Parenting matters: Supporting parents of children ages $0-8$. National Academies Press; 2016.

National Academies of Sciences Engineering and Medicine. Implementing evidence-based prevention by communities to promote cognitive, affective, and behavioral health in children: Proceedings of a workshop. National Academies Press; 2017.

National Academies of Sciences Engineering and Medicine. Communities in action: Pathways to health equity. National Academies Press; 2017.

National Academies of Sciences Engineering and Medicine. Training the Future Child Health Care Workforce to Improve the Behavioral Health of Children, Youth, and Families: Proceedings of a Workshop. Washington, DC: The National Academies Press; 2017.

National Academies of Sciences Engineering and Medicine. (2019). Vibrant and Healthy Kids: Aligning Science, Practice, and Policy to Advance Health Equity. The National Academies Press.

National Academies of Sciences Engineering and Medicine. (2019). The Promise of Adolescence: Realizing Opportunity for All Youth. The National Academies Press.

National Academies of Sciences Engineering and Medicine. Fostering healthy mental, emotional, and behavioral development in children and youth: A national agenda. National Academies Press; 2019.

National Academies of Sciences Engineering and Medicine. (2020). Promoting Positive Adolescent Health Behaviors and Outcomes: Thriving in the 21st Century. The National Academies Press.

National Academies of Sciences Engineering and Medicine. The State of Mental, Emotional, and Behavioral Health of Children and Youth in the United States: Proceedings of a Workshop. Washington, DC: The National Academies Press; 2020.

National Academy for State Health Policy. Referral and Care Coordination. In. Healthy Child Development State Resource Center 2020.

National Council of State Legislatures. Child Welfare. 2020; https:// www.ncsl.org/research/human-services/child-welfare.aspx. Accessed 08/11/2020.

National Research Council. From neurons to neighborhoods: The science of early childhood development. National Academies Press; 2000.

National Research Council, Medicine Io. Research Opportunities Concerning the Causes and Consequences of Child Food Insecurity and Hunger: Workshop Summary. Washington, DC: The National Academies Press; 2013.

National Research Council. Reforming juvenile justice: A developmental approach. National Academies Press; 2013.

National Scientific Council on the Developing Child. Connecting the Brain to the Rest of the Body: Early Childhood Development and Lifelong Health Are Deeply Intertwined: Working Paper No. 152020.

Obus EA, Brito NH, Sanlorenzo L, Rea C, Engelhardt L, Noble KG. Improving Adherence to Reach Out and Read: A Bookmark Intervention. 2017.

Osman, R., Manikam, L., \& Watters, K. (2018). Interventions to reduce premature births: a review of the evidence. The Lancet., 392, S69.

Peterson BE, Fontaine J, Cramer L, et al. Model Practices for Parents in Prisons and Jails: Reducing Barriers to Family Connections. Urban Institute; 2019.

Prinz, R. J., Sanders, M. R., Shapiro, C. J., Whitaker, D. J., \& Lutzker, J. R. (2009). Population-based prevention of child maltreatment: The US Triple P system population trial. Prevention science., 10(1), 1-12.

Ringel JS, Schultz D, Mendelsohn J, et al. Improving child welfare outcomes: balancing investments in prevention and treatment. Rand health quarterly. 2018;7(4).

Schneider, R. D. (2010). Mental health courts and diversion programs: A global survey. NY: Elsevier.

Schneider RD, Bloom H, Heerema M. Mental health courts: Decriminalizing the mentally ill. Irwin Law; 2000.

Schober MB, K. Medicaid Funding for Family and Youth Peer Support Programs in the United States. College Park, MD: University of Maryland School of Social Work: The Institute for Innovation and Implementation; 2020.

Sesame Street in Communities. Coping With Incarceration. Sesame Street in Communities https://sesamestreetincommunities.org/ topics/incarceration/.

Schofield, T. J., Lee, R. D., \& Merrick, M. T. (2013). Safe, stable, nurturing relationships as a moderator of intergenerational continuity 
of child maltreatment: A meta-analysis. Journal of Adolescent Health., 53(4), S32-S38.

The Rippel Foundation. A Typology of Potential Financing Structures for Population Health. In. Rethink Health: A Rippel Initiative2018:https://www.rethinkhealth.org/wp-content/uploa ds/2019/2009/RTH-TypologyChart_WB_Tab_1122018.pdf.

U.S. Department of Health and Human Services; Administration for Children and Families. The AFCARS Report. 2019.

U.S. Department of Health and Human Services; Administration for Children and Families. Head Start program facts: Fiscal year 2019. 2019.

U.S. Department of Health and Human Services; Administration for Children and Families, Office of Head Start, National Center on Parent, Family, and Community Engagement Strategies for Partnering with Child Welfare Agencies. 2020a; https://eclkc.ohs.acf. hhs.gov/community-engagement/article/head-start-programschild-welfare-partnerships. Accessed 09/03/2020.

U.S. Department of Health and Human Services; Administration for Children and Families, Office of Head Start, National Center on Parent, Family, and Community Engagement Engaging Families with Children in the Child Welfare System. 2020b; https://eclkc. ohs.acf.hhs.gov/sites/default/files/pdf/engaging-families-whenthere-is-child-welfare-involvement.pdf. Accessed 09/03/2020.

Washington State Institute for Public Policy. Benefit-Cost Results: Children's Mental Health. In:2020:https://www.wsipp.wa.gov/ BenefitCost?topicId=5.

World Health Organization. How effective are smoking cessation and nutritional interventions in preventing low birth weight? . 2020; https://www.euro.who.int/en/data-and-evidence/evidence-infor med-policy-making/publications/hen-summaries-of-networkmembers-reports/how-effective-are-smoking-cessation-and-nutri tional-interventions-in-preventing-low-birth-weight. Accessed 09/03/2020.

Zhou, J., Ko, J. Y., Haight, S. C., \& Tong, V. T. (2019). Treatment of substance use disorders among women of reproductive age by depression and anxiety disorder status, 2008-2014. Journal of Women's Health., 28(8), 1068-1076.

Publisher's Note Springer Nature remains neutral with regard to jurisdictional claims in published maps and institutional affiliations. 